\title{
Considerations about the service life prediction of reinforced concrete structures inserted in chloride environments
}

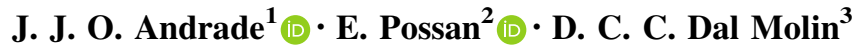

Received: 13 March 2017/ Accepted: 13 June 2017 / Published online: 29 June 2017

(C) Springer International Publishing AG 2017

\begin{abstract}
Nowadays an amount of reinforced concrete structures are presenting problems related with corrosion of reinforcement, mainly that induced by chloride ions. So, many studies are being accomplished to predict the necessary time for chloride ions reach the reinforcement, beginning the propagation of corrosive process. In this paper, three models were selected for analysis to determine their ability in properly predicting the chloride penetration in concrete structures: the solution of 2nd Fick's Law, the complete solution of 2nd Fick's Law, considering the variation of diffusion coefficient and the superficial concentration of chlorides in time; and a model proposed. Analysis of the formulations principles and assessment and applicability of equations were made, taking into account the adequate choice of parameters and variables involved, the difficulty to obtain these parameters, and if the models
\end{abstract}

\footnotetext{
J. J. O. Andrade

jairo.andrade@pucrs.br

E. Possan

epossan@gmail.com

D. C. C. Dal Molin

dmolin@ufrgs.br
}

1 Postgraduate Program in Materials Engineering andTechnology (PGETEMA), Pontifical Catholic University of Rio Grandedo Sul (PUCRS), Av. Ipiranga, 6681, Prédio 30, Porto Alegre, RS 90619-900, Brazil

2 Postgraduate Program in Civil Engineering (PGECI), FederalUniversity of Latin American Integration (UNILA), Av.Tancredo Neves, 6731, B1. 6, Foz do Iguaçu, PR 85867.970, Brasil

3 Postgraduate Program in Civil Engineering: Construction andInfrastructure (PPGCI), Federal University of Rio Grande do Sul)(UFRGS), Av. Osvaldo Aranha, 99, 7o andar, sala 706, Porto Alegre, RS 90035-190, Brasil represent properly the natural phenomena. In order to contribute with the service life prediction of the structures when inserted in saline environments, a mathematical model was developed based in a Focus Groups analysis. Some of the main characteristics of the proposed model are the logic applied for its development and the application easiness. This model was applied in a case study to verify the answer in relation to chloride penetration in some points of a reinforced concrete structure inserted in a saline area. The behavior of the model was consistent with the results of experimental investigations accomplished by other researchers.

Keywords Concrete $\cdot$ Service life $\cdot$ Chloride penetration . Modeling

\section{Introduction}

The development of new technologies, construction processes and building materials has encouraged the construction of more economical buildings. However, the high competitiveness of the sector and the reduction of production costs have a negative influence in constructions quality produced in Brazil over the past years. It is common to find constructions with levels of degradation higher than desired, with problems related to quality and durability due to execution failures and the appearance of pathological manifestations, which affects the aesthetics, safety, usability and the service life. In this way, several service life models, which can adequately describe the degradation process of reinforced concrete structures over time, have been developed. Many of these models are related with the corrosion of reinforcement, which is the predominant damage that occur in concrete structures, 
which attempt to model the penetration of the main aggressive agents responsible for the despassivation process: the chloride ions and the carbon dioxide.

Nowadays these have been a great effort by some researchers to model chloride penetration into concrete. The proposed formulations vary in complexity, but most are based on the assumption that at least some part of the process is diffusion controlled. It is essential that the parameters that are used in functions to predict degradation rates can be quantified by direct measurement or by inference [1]. Highly complex multi-variable functions that may be scientifically accurate in modeling the process may be limited by lack of quantifiable data for each parameter. At the opposite, simple empirical models based on a large number of observations may not be sufficiently sophisticated to deal with conditions outside the scope of the data used in developing the model. So, a compromise must be reached to achieve a model that is scientifically credible, is acceptable to practising engineers and has an acceptable level of reliability [1].

In general, the development of models of degradation is based in two approaches: one empirical and other phenomenological or complex. Empirical models, also called simplified models, are based on field or laboratory data adjustments or based on the experience of specialists, usually have analytical solutions. This group includes the models of Hamada [2], Ho and Lewis [3], Jiang, Lin and Cai [4], Possan [5], Andrade [6] among others. The complex or phenomenological models are based on physicochemical laws, as the laws of conservation of mass of $\mathrm{CO}_{2}$ and water and due to their complexity require numerical solutions. The formulations derived from these models are created based on knowledge and analysis of mechanisms and kinetics of degradation, especially in the Papadakis et al. [7], Saetta and Vitaliani [8]. Other factors that differentiate the mathematical models are presented in
Table 1, whose information was compiled from some literature works [9-13].

In general, empirical models are easier to apply, but simplifications can lead at less accurate results. The complex models consider a greater number of variables that have influence in degradation process, tending to a greater precision and generalization, but are more difficult to be applied.

Since Collepardi [14] published his application of 2nd Fick's Law, his assumption has been applied in many projects with aim of predicting chloride ingress into concrete [15]. This is expressed through the Eq. (1):

$$
\frac{\partial C}{\partial t}=D \frac{\partial^{2} C}{\partial x^{2}} \text {. }
$$

Assuming the chloride surface concentration and the chloride diffusion coefficient in concrete remain constant, the solution of the Eq. (1) can be represented by the Eq. (2):

$C(x, t)=C_{i}+\left(C_{s}-C_{i}\right) \operatorname{erfc}\left(\frac{x}{\sqrt{4 t D}}\right)$,

where $C(x, t)$ is the chloride concentration at a depth $x$ at the time $t ; C_{s}$ is the surface chloride concentration (\%); $C_{i}$ is the initial concentration of chloride in the concrete $(\%) ; t$ is the time (years); $D$ is the chloride diffusion coefficient ( $\mathrm{cm}^{2} /$ year); and erfc is the error-function complement.

However, it is observed that the diffusion coefficient tends to decrease with time, a function of the continuous changes in concrete structure [16, 17]. Besides, the chloride concentration tends to increase at the surface of structural elements in time [18, 19]. So, the chloride penetration in concrete could be better predicted if these considerations are incorporated in an adopted prediction form.

In this way, Mejlbro [20] solved the Eq. (1) considering that the diffusion coefficient and the surface chloride

Table 1 Empirical versus complex models [5]

\begin{tabular}{|c|c|c|}
\hline Aspect & Empirical models & Complex models \\
\hline Theoretical foundation & $\begin{array}{l}\text { Expertise from experts, historical data and } \\
\text { laboratory and field data }\end{array}$ & $\begin{array}{l}\text { Nature laws (physical and chemical), } \\
\text { algebraic formulations }\end{array}$ \\
\hline Input parameters & Generally simple, easy to obtain & $\begin{array}{l}\text { Usually require testing for determination- } \\
\text { some are difficult to obtain }\end{array}$ \\
\hline Precision & Associated error may be high & Tends to reduce errors \\
\hline Computational effort & Simple, in general, analytical & Complex, usually numerical \\
\hline Practical application & Easy & Difficult \\
\hline Extrapolation & Have influence in results reliability & If well elaborated can admit extrapolations \\
\hline Generalization & $\begin{array}{l}\text { Applicable to the intervals of information that } \\
\text { gave rise to the model }\end{array}$ & $\begin{array}{l}\text { Applicable to all situations governed by the } \\
\text { laws that comprise it }\end{array}$ \\
\hline
\end{tabular}


concentration are time-dependent. The author verified that the surface chloride concentration in concrete belongs to a certain family of functions, being represented by the Eq. (3):

$C_{s}=C_{i}+S\left[\left(t-t_{e x}\right) D_{a}\right]^{p}$,

where $C_{s}$ is the surface chloride concentration (\%); $C_{i}$ is the initial concentration of chloride in concrete $(\%) ; t$ is the time (years); $t_{e x}$ is the time of the first chloride exposure (years); $D_{a}$ is the diffusion coefficient in function of the time $\left(\mathrm{cm}^{2} /\right.$ year); and $S$ and $p$ is the constants determined through experimental fittings.

The factors $S$ and $p$ depend basically on the chloride levels in the environment, the cement type, and the admixtures present in concrete. Through data obtained from analysis in loco, the values of surface chloride concentration are collected and, starting from fittings, the values of these variables are obtained. The same are necessary to calculate the variation of surface chloride concentration in time for a certain structural element.

The variation of the diffusion coefficient in time is modeled through the Eq. (4):

$D_{a}=D_{\text {aex }}\left(\frac{t_{e x}}{t}\right)^{\alpha}$,

where $D_{a e x}$ is the initial diffusion coefficient ( $\mathrm{cm}^{2} /$ year); $t_{e x}$ is the time of the first chloride exposure (years); $\alpha$ is the exponent that depends on the w/c of concrete; $t$ is the time (years). [20]:

$a=3(0.55-w / c)$,

where $w / c$ is the water/cement ratio.

The initial diffusion coefficient $\left(D_{a e x}\right)$ denotes the value of the chloride diffusion coefficient at time $t$ is the $t_{e x}$, and, if this parameter is not determined by the Test Method NT Build 443 [21], it could be estimated from Eq. (6), obtained from adjusts of experimental results showed in Mejlbro [20]:

$D_{a e x}=50000 \times e^{\left(-\sqrt{\frac{23}{w / c}}\right)}$.

Thus, the model proposed by Mejlbro [20] presents the final form expressed by the Eq. (7):

$C(x, t)=C_{i}+S\left[D_{a}\left(t-t_{e x}\right)\right]^{p} \Psi_{p}\left(\frac{x}{\sqrt{4\left(t-t_{e x}\right) D_{a}}}\right)$,

where $\psi_{p}$ is the function tabulated by Mejlbro [20].

However, they are not clearly specified if all cement types obey the relationships showed above, as well as the variation of the w/c for each cement type. It is known that the complete solution proposed takes into consideration the parameters varying continually with time. Even so, more investigations should be made to verify if the relationship proposed are more adapted to represent satisfactorily the real phenomenon.

So, one of the principal challenges in developing a mathematical model for service life prediction is that many parameters, including material characteristics, climatic environment and construction method, will affect the service life provisions. Besides, the obtaining of some parameters used in a great majority of proposed models (e.g. the diffusion coefficient) is very difficult in laboratory experiments and/or in field investigations. Nevertheless, the aim of this investigation is to establish a usable, practical, and reliable mathematical model to predict the chloride penetration in concrete structures.

\section{Model development}

Another form of evaluating the chloride penetration in a structural element is to know the progress, with time, of the "forehead" that corresponds to a certain chloride concentration. Thus, it would be interesting to know the progress of a chloride concentration corresponding to $0.4 \%$ by cement mass $\left(C_{c r}\right)$, that it is at the maximum amount of chloride that can is allowed in a structural element at the reinforcement level. That value is a recommendation, not proved totally by tests.

In principle, the exponential function is more appropriate to represent the chloride penetration in time, where the mathematical representation of this principle is shown in Eq. (8):

$y_{0.4 \%}=k_{C l} \times t^{b}$,

where $y_{0.4 \%}$ is the depth of chloride ions penetration (equivalent to a chloride amount of $0.4 \%$ in relation to the cement mass), in $\mathrm{cm} ; k_{C l}$ is the chloride coefficient, in $\mathrm{cm}^{2} /$ year; $b$ is the coefficient to be determined; and $t$ is the time, in years.

The chloride coefficient $\left(k_{C l}\right)$ represents the "first-year ingress" of the critical chloride concentration $\left(C_{c r}\right)$ into concrete. It is known that in this parameter are related factors that have relationship to concrete characteristics (e.g. cement type, presence or not of admixtures and execution quality) and the environment (e.g. temperature, relative humidity, chloride presence) that influence in chloride transport. In existing structures, the determination of the same can be accomplished with a certain easiness through the knowledge of the chloride profile within a certain time $t$, where the $k_{C l}$ value is easily found by application of Eq. (8).

However, the determination of the $k_{C l}$ value for planned structures is very difficult, because the knowledge of the 
holistic effect existing between the several factors that influence chloride penetration in a structure are quite difficult to model.

In this way, was developed a new mathematical model to represent the chloride penetration into the concrete [6]. First was considered that the chloride penetration depends basically of some characteristics related to concrete and the environment, where the main factors that influence in the chloride transport are presented in Table 2. Thus, it is assumed that the $k_{C l}$ value change is a function of the parameters presented, where the penetration would be represented in a generic form by Eq. (9):

$y_{0.4 \%}=\left[f\left(f_{c k}, U R, T, C l, K_{1}, K_{2}, A d\right)\right] \times t^{b}$.

The chloride penetration is proportional to temperature, relative humidity and external chloride concentration; and is inversely proportional to concrete strength, cement type, and type/amount of admixture. Thus, using this principle and considering which have a multiplicative effect among the basic variables, the general form of the model proposed is shown in Eq. (10):

$y_{0.4 \%}=\frac{K_{0} \times U R^{b_{1}} \times T^{b_{2}} \times C l^{b_{3}}}{K_{1} \times f_{c k}^{b_{4}} \times K_{2} \times(1+A d)^{b_{5}}} \times t^{b_{6}}$,

where $K_{0}$ is the general constant; and $b_{1}-b_{6}$ is the variable coefficients.

The realization of a complete experimental work to establish the coefficient values from $b_{1}$ to $b_{6}$, and the constant $K_{0}$ for all possible variable combinations (related to concrete and environment), is very difficult due to the great amount of resources needed and the time needed to obtain results. It should be noted that there are several forms of data collection (Table 3), being the focus group, or knowledge of experts one of them. This technique is used when there is no adequate database, as in the study under analysis.

Since the existing experimental results of concrete degradation by chloride ions are fragmented, implying

Table 2 Main factors that influence in chloride penetration

\begin{tabular}{lll}
\hline & Symbol & Unit \\
\hline Concrete characteristics & & \\
Concrete strength (28 days) & $f_{c k}$ & $\mathrm{MPa}$ \\
Cement type & $K_{1}$ & - \\
Admixture type & $K_{2}$ & - \\
Amount of admixture & $\mathrm{Ad}$ & $\%^{\mathrm{a}}$ \\
Environment characteristics & & \\
Mean temperature $\left({ }^{\circ} \mathrm{C}\right)$ & $T$ & ${ }^{\circ} \mathrm{C}$ \\
Relative humidity $(\%)$ & $\mathrm{UR}$ & $\%$ \\
Chloride concentration $(\%)$ & $\mathrm{Cl}$ & $\%^{\mathrm{a}}$ \\
\hline
\end{tabular}

${ }^{a}$ By cement mass difficulties in the generalization and modeling of data, as well as in the transposition of these to real situations, for the elaboration of the model proposed in this paper did necessary to obtain/collect them. As the realization of an experiment, which contemplated all the variables of influence on concrete degradation due to chloride ions, would require a lot of time and resource, data collection of this study is based on expert knowledge, using the focal group technique to obtain the data that gave origin to the model.

Focus groups are forums that bring together a small group of individuals to talk about a topic of interest. Basically, it can be considered a group interview, although not with the sense of alternation where a researcher questions and the participants respond. Instead, its essence consists in the interaction between individuals, based on topics that are promoted by the researcher, who usually assume the role of moderator of the session [22].

In engineering, the works that employ this technique are rare $[5,6,23]$. To use data from the literature, it should be noted that there are several studies on concrete degradation due to chloride penetration. However, it is difficult to construct a robust database, since the studies employ different methodologies. Also they do not contemplate all the variables of influence of the concrete degradation, being that the majority of the cases are of accelerated experiments.

The proposed model requires real degradation data or natural test data from concrete degradation due to chloride penetration. Accelerated data is difficult to use in practice because the damage acceleration coefficient is unknown.

So, what took place was an experiment in focus groups, where specialists were invited to answer some questions about Durability of Structures. The Focus Group is recommended to give orientation for investigations or actions in new research fields, to generate hypothesis based in specialists perception, to evaluate different research situations and to generate additional information to a study on a wide scale [22, 24]. This tool is used in the study of many exploratory fields, such as Social Sciences and Production Engineering, and has lead to very interesting results. The first application of this methodology is been made in Concrete Technology, where the results will be adequately evaluated.

So, a group composed of 11 researchers from some Universities, ${ }^{1}$ specialists in Concrete Technology and Durability of Structures fields was gathered. The collected data were analyzed through non-linear regression, to obtain the final model represented by the Eq. (11):

\footnotetext{
${ }^{1}$ University of Brasília, University of Campinas, Federal University of Rio Grande do Sul, Polytechnic School of the University of São Paulo (all from Brazil) and University of California, at Berkeley.
} 
Table 3 Potential sources of degradation data for concrete structures [5]

Information, data or indicators

\begin{tabular}{|c|c|c|}
\hline Type & Origin & Observation \\
\hline Objective & $\begin{array}{l}\text { Accelerated material performance tests, providing } \\
\text { Maintenance, repair and rehabilitation performance indicators } \\
\text { Durability indicators } \\
\text { Protection performance indicators (steel paints, anodic and } \\
\text { cathodic protection, among others) } \\
\text { Aggressiveness of the environment. } \\
\text { In situ research, providing } \\
\text { The abovementioned indicators } \\
\text { The speed and intensity of the degradation process of real } \\
\text { buildings }\end{array}$ & $\begin{array}{l}\text { Information from these sources has a high potential for use. } \\
\text { Ideally, this information should be grouped into a database to } \\
\text { facilitate access to information and increase the reliability of } \\
\text { the results presented. These databases can be formed with data } \\
\text { from theses, dissertations, academic articles, case studies, } \\
\text { among other reliable sources. However, accelerated test data } \\
\text { need to be used with caution, since for prediction studies it is } \\
\text { necessary to use a coefficient of acceleration of degradation }\end{array}$ \\
\hline & $\begin{array}{l}\text { Indicators of performance and efficiency provided by the } \\
\text { manufacturer or maintainer of the component, subsystem and } \\
\text { system of the building }\end{array}$ & $\begin{array}{l}\text { This information is also useful for determining or evaluating } \\
\text { warranty periods. }\end{array}$ \\
\hline Subjective & Expert experience & $\begin{array}{l}\text { In the absence of real data, information from expert knowledge } \\
\text { can be used. For this, the focus group and the Delphi method } \\
\text { can be employed }\end{array}$ \\
\hline
\end{tabular}

$y_{0.4 \%}=\frac{7.35 \times U R^{0.7} \times T^{0.1} \times C l^{0.7}}{K_{1} \times f_{c k} \times K_{2} \times(1+A d)^{0.2}} \times \sqrt{t}$,

where $y_{0.4 \%}$ is the position of critical chloride concentration $\left(C_{c r}\right)$ from the concrete surface $(\mathrm{mm}) ; U R$ is the relative humidity of the atmosphere (\%); $T$ is the environmental temperature $\left({ }^{\circ} \mathrm{C}\right) ; \mathrm{Cl}$ is the environmental chloride concentration (\%); $K_{1}$ is the factor that varies in function of the type of cement used in the concrete production; $f_{c k}$ is the compressive strength (28 days) (MPa); $K_{2}$ is the factor that varies in function of the admixture type used in concrete production; $A d$ is the amount of admixture in concrete (\%); and $t$ is the time (years).

It can be observed that the value of coefficient $b_{6}$ determined by analysis is equal at 0.5 , and is consistent with the theory that considers that the chloride penetration as the proportional at square-root of time [15, 25]. The factors $K_{1}$ and $K_{2}$, obtained from the Focus Groups analysis are presented in Tables 4 and 5 , respectively.

\section{Application}

In order to verify that the formulation properly represents the natural phenomena, the results obtained from an inspection analysis (chloride profiles) [26] were used to partially validate the model. Was realized a series of analyses in a structure located in a saline area in South of Brazil, that presents 22 years of service life. The analyses presented here were based on study done at two different points, designated as $\mathrm{P} 1$ and $\mathrm{P} 2$, and were separated by a vertical distance of approximately $1.5 \mathrm{~m}$ in the same
Table 4 Values of $K_{1}$ in function of the cement type

\begin{tabular}{ll}
\hline$K_{1}$ & ASTM cement type \\
\hline 0.98 & I (SM) \\
1.05 & I (PM) \\
1.21 & IS \\
1.17 & IP \\
0.95 & III \\
\hline
\end{tabular}

Table 5 Values of $K_{2}$ in function of admixture type

\begin{tabular}{ll}
\hline$K_{2}$ & Type of admixture \\
\hline 1.00 & Silica fume \\
0.97 & Metakaolin \\
0.76 & Rice husk ash \\
\hline
\end{tabular}

Table 6 Characteristics of the structural element and environment [26]

\begin{tabular}{llc}
\hline Property & P1 & P2 \\
\hline Compressive strength at 28 days (MPa) & 24 & 23 \\
w/c ratio & 0.44 & \\
Cement type & ASTM Type IP \\
Cement content $\left(\mathrm{kg} / \mathrm{m}^{3}\right)$ & 403 \\
Mean temperature $\left({ }^{\circ} \mathrm{C}\right)$ & 25 & \\
Relative humidity $(\%)$ & 80 & \\
\hline
\end{tabular}

element (marine pier). The concrete properties and environment characteristics for the analyzed points are presented in Table 6, where the chloride profiles obtained from concrete samples at the points are presented in Fig. 1. 


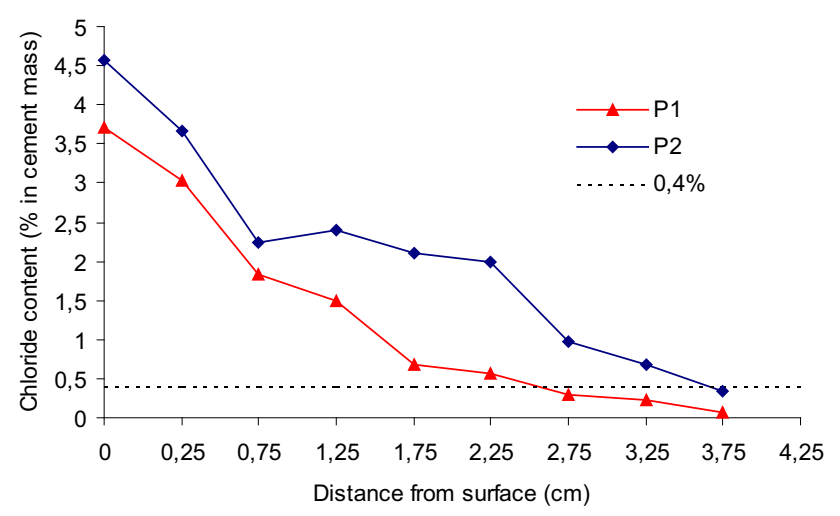

Fig. 1 Chloride profiles in analyzed points

Table 7 Surface concentration and diffusion coefficient for the analyzed points

\begin{tabular}{lll}
\hline Point & $\mathrm{C}_{\mathrm{s}}(\%)$ & $\mathrm{D}\left(\mathrm{cm}^{2} /\right.$ year $)$ \\
\hline P1 & 3.45 & 0.06 \\
P2 & 3.99 & 0.13 \\
\hline
\end{tabular}

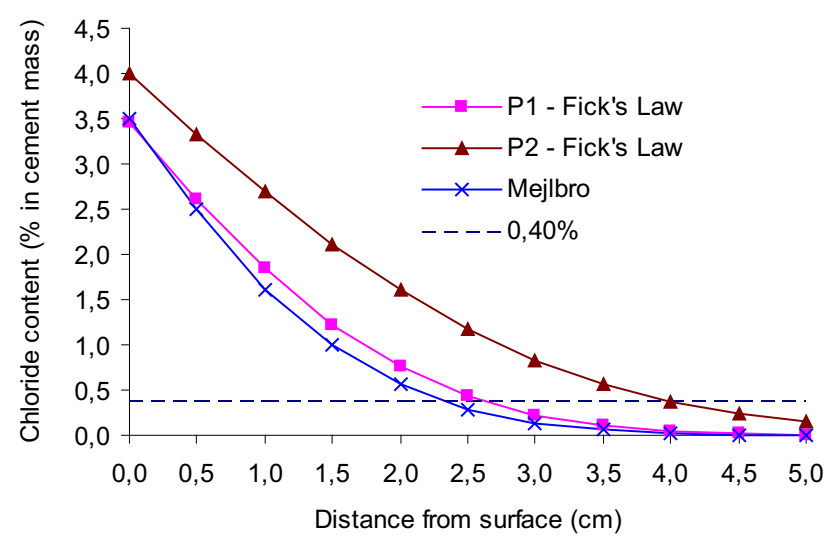

Fig. 2 Profiles obtained from best fit adjust from 2nd Fick's Law and the Mejlbro [20] formulation

The values of the surface chloride concentration and the diffusion coefficient were obtained by fitting the profiles found by the least square method, being used for Eq. (2). The best fits results for each analyzed point are presented in Table 7. With the values presented in Tables 5 and 6 , the theoretical penetration profiles were calculated through fittings in the expressions of Fick (Eq. 2) and Mejlbro [20] (Eq. 7), as can be observed in Fig. 2.
Comparing the Figs. 1 and 2, it is observed that the adjustment achieved by 2nd Fick's Law represents a good agreement with the analyzed points. However, the fit done through the model proposed by Mejlbro [20] presents a good agreement only for the point P1. In the case of the 2nd Fick's Law, individual values for $C_{s}$ and $D$ for each analyzed point were obtained, where a clear variation exists between the surface concentration and the diffusion coefficient for each individual point. In Mejlbro [20] model, the variation sources are related to environmental parameters $(S$ and $p$ ) and the $w / c$ of the concrete. As the analyzed points meet very close, it is assumed that the concrete characteristics don't vary significantly, and the parameters that are necessary for the resolution of the model are the same ones for the two points, leading to the same curve format.

An attempt was made evaluate the depth reached by a chloride concentration equal at $0.4 \%$ in relation to the cement mass, considering the models presented previously. The data presented in Tables 5 and 6 were used, with the results shown in Table 8.

It can be observed that the results of the proposed model (Eq. 11) show values near those measured in structure. Possan and Andrade [27] using Markov chain, obtained similar results. The small variation found can be considered as acceptable, because the same happens mainly due to the inherent variability existent in measures of the chloride concentration in structural elements.

It is highlighted that the model made use of data obtained from expert knowledge, however its validation was conducted with real degradation data, indicating that the construction/modeling process has scientific rigor.

\section{Conclusions}

This paper shows some considerations about some models used to predict the chloride penetration in concrete. The models proposed by Fick and Mejlbro [20] are extremely useful, but are applicable only for analysis of existing structures where the data collected through inspections give information for service life predictions. However, for a structure under construction, the prediction of service life realized through these models still has a low reliability. There are so many constants involved in analysis, where the correlation about them is very questionable.
Table 8 Penetration depth of the critical concentration of chloride ions $\left(C_{c r}\right)$ calculated by the presented models

\begin{tabular}{lllll}
\hline Point & \multicolumn{3}{l}{$y_{0.4 \%}(\mathrm{~cm})$} & \\
\cline { 2 - 5 } & Measured in situ & 2nd Fick's Law (Eq. 2) & Mejlbro [20] (Eq. 7) & Model proposed (Eq. 11) \\
\hline P1 & 2.55 & 2.55 & 2.25 & 2.94 \\
P2 & 3.63 & 3.87 & 2.25 & 3.25 \\
\hline
\end{tabular}


To improve this prediction a penetration model is proposed that considers the concrete characteristics and the environmental conditions associated with chloride transport. A basic characteristic of this model is its easy application, where the variables incorporated in formulation are easily obtained through data collection and/or by direct measurements.

Comparative analysis was made among the models in order to verify the penetration of chloride ions into concrete. A structure located in a marine atmosphere in Brazil, that presents 22 years of service life, was used as a case study. The chloride profiles at two different points from the structure were compared, and the results showed that the proposed model gives values of chloride penetration similar to those determined by inspections of the structure.

Thus, the proposed model can be used to estimate the service life of reinforced concrete structures. However, the lack of available data is a problem found to complete validation of the model. During the inspection in a structure, some data related to specific micro-environmental conditions are not generally collected, and just a characterization of the macroenvironment is made. Also researchers often do not have access to data from the construction period for their analysis, such as the cement type used or compressive strength of concrete (at 28 days). In this way, it would be interesting that the presented model be used by a great amount of researchers, and be refined in the future to give better predictions.

The proposed model is easy to apply, however it presents uncertainties regarding the inherent variability of concrete and its degradation. However, the model can be used as a tool to approximate the reality of concrete degradation due to the action of chloride in the design for durability.

For future studies, it is suggested the acquisition of new natural degradation data for calibration of the coefficients of the model. Data can be obtained by performing experimental designs such as fractional factorial design, split-plot, $2 \mathrm{k}$, or by compiling experimental data from real structures or nonaccelerated tests in the literature. These data can be modeled in order to refine the model coefficients via linear or nonlinear modeling, artificial neural networks, among other techniques available for complex modeling.

Acknowledgements The authors gratefully acknowledge to A. Nepomuceno, V. A. Paulon, P. Helene, P. J. M. Monteiro, R. Cremonini, A. Masuero, A. Abreu and F. Vieira for their time and assistance in this investigation.

\section{References}

1. Bamforth $P$ (1996) Predicting the risk of reinforcement corrosion in marine structures. In: Mehta PK (ed) Odd E. Gjorv symposium on concrete for marine structures, New Brunswick
2. Hamada M (1969) Neutralization of concrete and corrosion of reinforcing steel. In: Proceeding of 5th international symposium on the chemistry of the cement, Tokyo, vol 3, pp 346-351

3. Ho DWS, Lewis RK (1987) Carbonation of concrete and its prediction. Cem Concr Res 17(3):489-504. doi:10.1016/00088846(87)90012-3

4. Jiang L, Lin B, Cai Y (2000) A model for predicting carbonation of high-volume fly ash concrete. Cem Concr Res 30(5):699-702. doi:10.1016/S0008-8846(00)00227-1

5. Possan E (2010) Modeling of carbonation and service life prediction of reinforced concrete structures in an urban environment. $\mathrm{PhD}$ thesis, Federal University of Rio Grande do Sul, Porto Alegre

6. Andrade JJO (2001) Contribuição à Previsão da Vida Útil das Estruturas de Concreto Armado Atacadas pela Corrosão da Armadura: Iniciação por Cloretos. Tese, UFRGS, Porto Alegre

7. Papadakis VG, Vayenas CG, Fardis MN (1991) Fundamental modeling and experimental investigation of concrete carbonation. Mater J. doi:10.14359/1863

8. Saetta AV, Vitaliani RV (2004) Experimental investigation and numerical modeling of carbonation process in reinforced concrete structures: part I: theoretical formulation. Cem Concr Res 34(4):571-579. doi:10.1016/j.cemconres.2003.09.009

9. Meyer WJ (2004) Concepts of mathematical modeling. Dover Science, New York

10. Muntean A, Meier SA, Peter MA, Böhm M, Kropp J. A note on limitations of the use of accelerated concrete-carbonation tests for service-live predictions. Scientific Report. Bremen: Universität Bremen2005. Report No.: 05-04

11. Pauletti C (2009) Estimativa da carbonatação natural de materiais cimentícios a partir de ensaios acelerados e de modelos de predição. Tese, UFRGS, Porto Alegre

12. Thiéry M (2005) Modélisation de la carbonatation atmosphérique das bétons-prise en compte das effets cinétiques et de l'évolution de la microstructure et de l'état hydrique. Thèse de Doctorat, Ecole Nationale des Ponts et Chaussées, Paris

13. Bender EA (2000) Introduction to mathematical modeling. Dover Publications, New York

14. Collepardi M, Marcialis A, Turriziani R (1972) Penetration of chloride ions into cement paste and concrete. Am Ceram Soc 53:534-535. doi:10.1111/j.1151-2916.1972.tb13424.x

15. Maage M, Helland S, Poulsen E, Vennesland O, Jan Erik C (1996) Service life prediction of existing concrete structures exposed to marine environment. Mater J. 93(6):602-608. doi:10. $14359 / 9866$

16. Liang M, Wang K, Liang C (1999) Service life prediction of reinforced concrete structures. Cem Concr Res 29(9):1411-1418. doi:10.1016/S0008-8846(99)00109-X

17. Boddy A, Bentz E, Thomas M, Hooton R (1999) An overview and sensitivity study of a multimechanistic chloride transport model. Cem Concr Res 29(6):827-837. doi:10.1016/S00088846(99)00045-9

18. Uji K, Matsuoka Y, Maruya T (1990) Formulation of an equation for surface chloride content of concrete due to permeation of chloride. In: Corrosion of reinforcement in concrete. Society of Chemical Industry. London, pp 258-267

19. Amey SL, Johnson DA, Miltenberger MA, Farzam H (1998) Predicting the service life of concrete marine structures: an environmental methodology. ACI Struct J 95(2):205-214. doi:10. $14359 / 540$

20. Mejlbro L (1996) The complete solution of Fick's second law of diffusion with time-dependent diffusion coefficient and surface concentration. In: Sandberg P (ed) Durability of concrete in saline environment, Lund

21. NORDTEST (1995) Concrete hardened: accelerated chloride penetration. Espoo, Finland: NT BUILD 443 
22. Morgan DL (1997) Focus groups as qualitative research, 2nd edn. SAGE Publications, London

23. Bust AG, Gibb F, Haslam RA (2005) Manual handling of highway kerbs: focus group findings. Appl Ergon 36(4):417-425. doi:10.1016/j.apergo.2004.05.005

24. Krueger RA (1994) Focus groups: a practical guide for applied research, 2nd edn. SAGE Publications, Thousand Oaks

25. Andrade C (1999) Chloride penetration modeling. In: Meyer H-G, Siemes T (eds) CEN TC 104 and Duranet Workshop Design of Durability of Concrete, Berlin, p 5
26. Guimarães ATC (2000) Service life of reinforced concrete structures in marine environment. D.Sc. thesis, USP, São Paulo 27. Possan E, Andrade JJO (2014) Markov Chains and reliability analysis for reinforced concrete structure service life. Mater Res 17(3):593-602. doi:10.1590/S1516-14392014005000074 